\title{
Electronic and Magnetic Properties of Ca-Doped Mn-Ferrite
}

\author{
M. UstundaĞ $\breve{G}^{*}$ AND M. Aslan \\ Sakarya University, Physics Department, Sakarya, Turkey
}

\begin{abstract}
Spinel ferrite structures have vast applications, from microwave to radio frequencies. In order to acquire new electronic and optical behavior, divalent cations can be added to normal spinel ferrite structure. This way it is possible to facilitate its usage in material and science technology. In this work we have analyzed the impact of $\mathrm{Ca}$ addition to normal spinel manganese ferrite on electronic and magnetic properties by the first-principles calculations. For the exchange-correlation functional, Wu-Cohen, generalized gradient approximation method was used for electron-electron interactions. The calculation of electronic band structures is based on full potential linear augmented plane wave method. The calculated density of states shows that the addition of Ca ions has a significant impacts on the electronic and magnetic structure.
\end{abstract}

DOI: 10.12693/APhysPolA.130.362

PACS/topics: 71.15.Mb, 71.20.-b, 75.50.Gg

\section{Introduction}

Spinel ferrite structures have great impact on technologies, particularly in high frequency transformer, microwave and magnetic recording applications, in antennae and various microwave and radar devices [1-2]. Normal spinel structure is formulated as $\mathrm{AFe}_{2} \mathrm{O}_{4}$ where $\mathrm{A}$ is a divalent ion, generally transition metal $(\mathrm{A}=\mathrm{Mn}$ and $\mathrm{Ca}$, in this study) ions occupy A sites and trivalent ions $\left(\mathrm{Fe}^{+3}\right)$ occupy only B sites. In this study, the effects of the substitution of $\mathrm{Mn}$ with $\mathrm{Ca}$ in $\mathrm{MnFe}_{2} \mathrm{O}_{4}$ structure on electronic and magnetic properties are studied. Spinel structures $\mathrm{MnFe}_{2} \mathrm{O}_{4}$ and $\mathrm{Ca}_{0.5} \mathrm{Mn}_{0.5} \mathrm{Fe}_{2} \mathrm{O}_{4}$ are investigated using density functional calculations. The article is organized as follows: the method and calculation is explained in Section 2, and the electronic and magnetic properties of $\mathrm{MnFe}_{2} \mathrm{O}_{4}$ and $\mathrm{Ca}_{0.5} \mathrm{Mn}_{0.5} \mathrm{Fe}_{2} \mathrm{O}_{4}$ ferrite structures are explained in Section 3, finally, the conclusions are given in Section 4.

\section{Method and calculation}

First principles calculations for $\mathrm{AFe}_{2} \mathrm{O}_{4}$ type ferrite compounds are performed using the full potential linearized augmented plane wave (FP-LAPW) [3] method as implemented in WIEN2k [4] code within the framework of density functional theory (DFT). The exchange and correlation effects are treated using generalized gradient approach (GGA) based on Perdew et al. [5]. To get the total energy convergence, we have expanded the KhonSham wave functions up to $R_{\mathrm{MT}} K_{\max }=7$ ( $R_{\mathrm{MT}}$ are the plane wave radii and $K_{\max }$ is the maximum reciprocal lattice vector). Partial waves used inside atomic spheres have been expanded up to $l_{\max }=10$. In charge density Fourier expansion, magnitude of the largest vector $G$ is equal to $12 R y^{1 / 2}\left(G_{\max }=12 R y^{1 / 2}\right)$. The cut-off energy for separating core from valance states is set to $-7 R y$.

\footnotetext{
* corresponding author; e-mail: mustundag@sakarya.edu.tr
}

The standard special $k$-points technique of Monkhorst and Pack (MP) [6] is used for accurate Brillouin zone integrations. We have used $6 \times 6 \times 6 \mathrm{MP}$ meshes and 16 special $k$-points are taken in the irreducible wedge of the Brillouin zone.

\section{Results and discussions}

\subsection{Structural properties}

DFT calculations were performed for crystal structures with space group $227 \mathrm{Fd} 3 \mathrm{~m}$ for $\mathrm{MnFe}_{2} \mathrm{O}_{4} .2 \times 2 \times 2$ supercell is built on this structure to model $\mathrm{Ca}_{0.5} \mathrm{Mn}_{0.5} \mathrm{Fe}_{2} \mathrm{O}_{4}$ ferrite structure. The calculated lattice parameters $a$, bulk modulus $B$, first derivative of bulk modulus $B^{\prime}$ and band gap energies of studied materials are shown in Table I. Lattice parameter of $\mathrm{MnFe}_{2} \mathrm{O}_{4}$ are in good agreement with other studies for $\mathrm{MnFe}_{2} \mathrm{O}_{4}$. When divalent $\mathrm{Ca}$ atoms are added to $\mathrm{MnFe}_{2} \mathrm{O}_{4}$ the lattice parameter and $B^{\prime}$ increase, whereas the bulk modulus and $E_{\mathrm{g}}$ decrease, meaning that the material becomes softer.

TABLE I

The calculated lattice parameters $a$, bulk modulus $B$, first derivative of bulk modulus $B^{\prime}$ and band gap energies of $\mathrm{MnFe}_{2} \mathrm{O}_{4}$ and $\mathrm{Ca}_{0.5} \mathrm{Mn}_{0.5} \mathrm{Fe}_{2} \mathrm{O}_{4}$.

\begin{tabular}{c|c|c|c|c|c}
\hline \hline Material & $\begin{array}{c}a \\
{[\AA]}\end{array}$ & $\begin{array}{c}B \\
{[\mathrm{GPa}]}\end{array}$ & $B^{\prime}$ & $\begin{array}{c}E_{\mathrm{g}, \mathrm{up}} \\
{[\mathrm{eV}]}\end{array}$ & $\begin{array}{c}E_{\mathrm{g}, \text { down }} \\
{[\mathrm{eV}]}\end{array}$ \\
\hline & 8.44 & & & & 1.47 \\
$\mathrm{MnFe}_{2} \mathrm{O}_{4}$ & $8.49[2]$ & 146.20 & 2.1493 & $\begin{array}{c}1.25[8](\mathrm{exp}) \\
8.43[7]\end{array}$ & $0.4[7]$ \\
& $\begin{array}{c}8.36[8](\mathrm{exp}) \\
\end{array}$ & & & & 0 \\
\hline $\mathrm{Ca}_{0.5} \mathrm{Mn}_{0.5} \mathrm{Fe}_{2} \mathrm{O}_{4}$ & 8.5715 & 90.30 & 8.9695 & 1.28 & 0.045
\end{tabular}

\subsection{Electronic and magnetic properties}

The calculated electronic band gap and DOS in spin down state for $\mathrm{MnFe}_{2} \mathrm{O}_{4}$ is given in Fig. $1 . \mathrm{MnFe}_{2} \mathrm{O}_{4}$ has zero band gap in spin down state, whereas it is seen in Fig. 2 that in spin up state it has a band gap of $1.47 \mathrm{eV}$, which is an indication of half metallic behavior. The $\mathrm{O}$ atoms are effective at the core level of DOS structure of $\mathrm{MnFe}_{2} \mathrm{O}_{4}$ in spin down state. The wavefunctions of $\mathrm{Fe}$ 

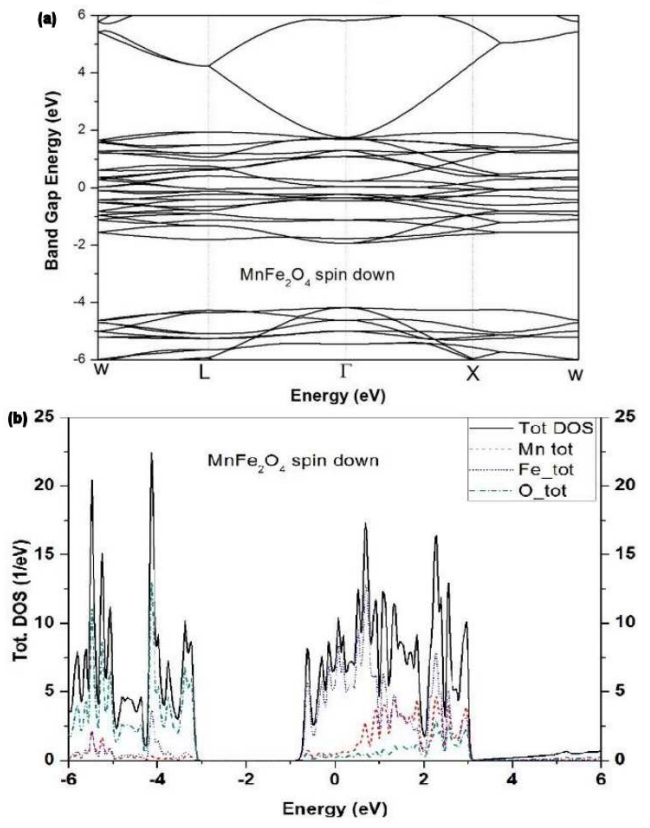

Fig. 1. Calculated (a) electronic band structure and (b) DOS in spin down state for $\mathrm{MnFe}_{2} \mathrm{O}_{4}$.
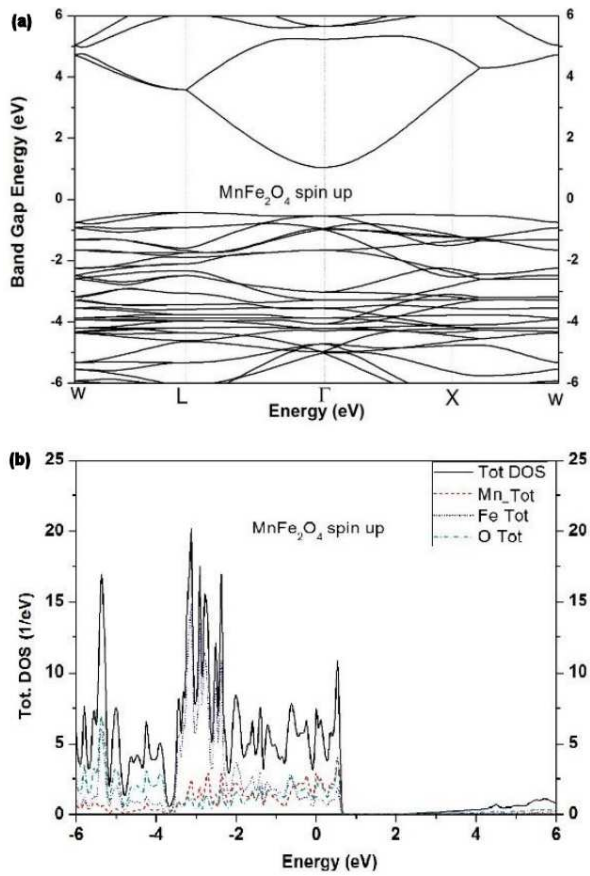

Fig. 2. Calculated (a) electronic band structure and (b) DOS in spin up state for $\mathrm{MnFe}_{2} \mathrm{O}_{4}$.

atoms in the valance region are denser than those of the other atoms, as seen in Fig. 1.

The DOS structure for $\mathrm{MnFe}_{2} \mathrm{O}_{4}$ in spin up state is represented in Fig. 2. Fe atoms have a great impact on DOS in the -2 and $-4 \mathrm{eV}$ region, but near the valance region, all atoms have nearly the same effect.

The calculated electronic band gap and DOS for $\mathrm{Ca}_{0.5} \mathrm{Mn}_{0.5} \mathrm{Fe}_{2} \mathrm{O}_{4}$ in spin down state is given in Fig. 3 .
The half metallic behavior has disappeared with the addition of Ca since it has a band gap of $0.045 \mathrm{eV}$ in spin down state and it has $1.28 \mathrm{eV}$ band gap in spin up state, as shown in Fig. 3 and Fig. 4, respectively.
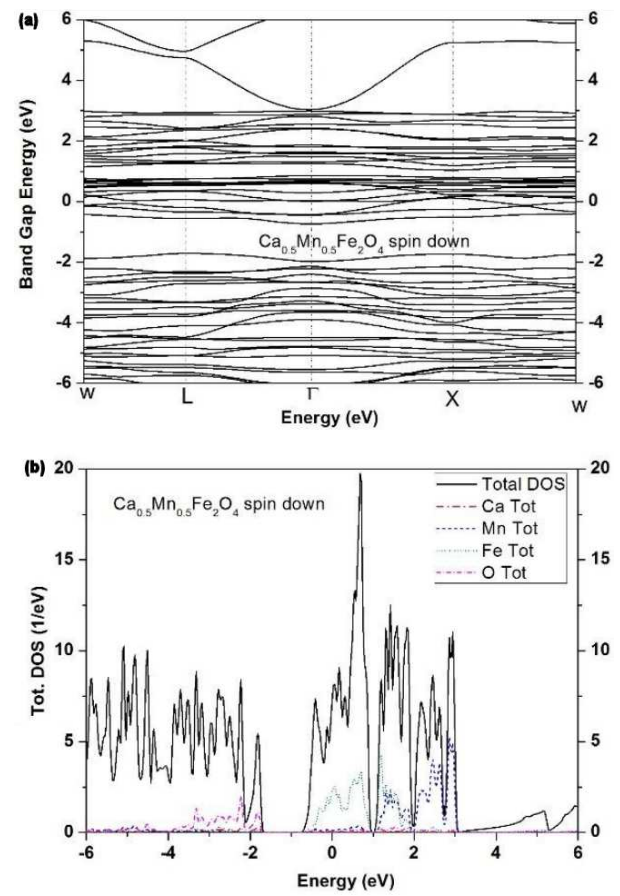

Fig. 3. Calculated (a) electronic band structure and (b) DOS in spin down state for $\mathrm{Ca}_{0.5} \mathrm{Mn}_{0.5} \mathrm{Fe}_{2} \mathrm{O}_{4}$.
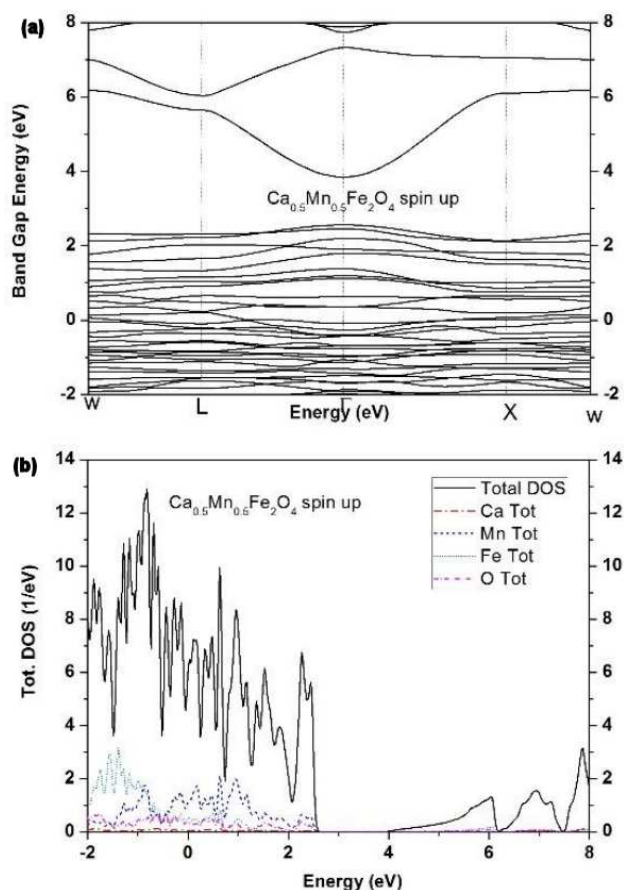

Fig. 4. Calculated (a) electronic band structure and (b) DOS in spin up state for $\mathrm{Ca}_{0.5} \mathrm{Mn}_{0.5} \mathrm{Fe}_{2} \mathrm{O}_{4}$. 
$\mathrm{Ca}$ addition to $\mathrm{MnFe}_{2} \mathrm{O}_{4}$ increases the $E_{\mathrm{g}}$ in spin down state while it decreases the band gap in spin up states. From Fig. 3, near the valance and conduction bands region the total peak is caused mostly by $\mathrm{Mn}$ and Fe atoms, while Ca atoms have very little effect on DOS in both, the conduction and the valance band regions. On the other hand, in spin up state, as shown in Fig. 4, near the valance band region $\mathrm{Mn}$ and $\mathrm{O}$ atoms have a much higher contribution to total DOS when compared to other atoms in $\mathrm{Ca}_{0.5} \mathrm{Mn}_{0.5} \mathrm{Fe}_{2} \mathrm{O}_{4}$.

Total magnetic moment of the cell and partial magnetic moment of the atoms is given in Table II. It can be seen from the table that $\mathrm{Ca}$ addition to $\mathrm{MnFe}_{2} \mathrm{O}_{4}$ increases the partial magnetic moment of the atoms in $\mathrm{Ca}_{0.5} \mathrm{Mn}_{0.5} \mathrm{Fe}_{2} \mathrm{O}_{4}$. On the other hand the total magnetic moment of the cell is decreased by $\mathrm{Ca}$ addition.

TABLE II

Total magnetic moment of the cell and partial magnetic moments of the single atoms in $\mathrm{MnFe}_{2} \mathrm{O}_{4}$ and $\mathrm{Ca}_{0.5} \mathrm{Mn}_{0.5} \mathrm{Fe}_{2} \mathrm{O}_{4}$.

\begin{tabular}{c|c|c|c|c|c}
\hline \hline Material & $\begin{array}{c}\mathrm{Ca} \\
{\left[\mu_{\mathrm{B}}\right]}\end{array}$ & $\begin{array}{c}\mathrm{Mn} \\
{\left[\mu_{\mathrm{B}}\right]}\end{array}$ & $\begin{array}{c}\mathrm{Fe} \\
{\left[\mu_{\mathrm{B}}\right]}\end{array}$ & $\begin{array}{c}\mathrm{O} \\
{\left[\mu_{\mathrm{B}}\right]}\end{array}$ & $\begin{array}{c}\text { Total } \\
\text { cell }\left[\mu_{\mathrm{B}}\right]\end{array}$ \\
\hline $\mathrm{MnFe}_{2} \mathrm{O}_{4}$ & $* * * * * *$ & 1.191 & 2.923 & 0.145 & 21.878 \\
$\mathrm{Ca}_{0.5} \mathrm{Mn}_{0.5} \mathrm{Fe}_{2} \mathrm{O}_{4}$ & 0.0298 & 3.764 & 3.261 & 0.180 & 18.918
\end{tabular}

\section{Conclusions}

We have investigated electronic and magnetic properties of $\mathrm{MnFe}_{2} \mathrm{O}_{4}$ and $\mathrm{Ca}_{0.5} \mathrm{Mn}_{0.5} \mathrm{Fe}_{2} \mathrm{O}_{4}$ ferrites by using density functional theory, based on the full potential linearized augmented plane wave method as implemented in the WIEN2k. We have explained the effect of $50 \% \mathrm{Ca}$ addition to $\mathrm{MnFe}_{2} \mathrm{O}_{4}$ on band gap, DOS and magnetic moments. It is clearly seen from our results that $\mathrm{MnFe}_{2} \mathrm{O}_{4}$ has half metallic, while $\mathrm{Ca}_{0.5} \mathrm{Mn}_{0.5} \mathrm{Fe}_{2} \mathrm{O}_{4}$ has a semiconducting behavior. We hope that our results can be used to cover the lack of data in the literature for Ca-doped $\mathrm{MnFe}_{2} \mathrm{O}_{4}$ ferrite.

\section{References}

[1] X. Zuo, B. Barbiellini, C. Vittoria, J. Mag. Mag. Mat. 272-276, 306 (2004).

[2] R. Singh, M. Gupta, R. Gupta, Phys. Rev. B 65, 064432 (2002).

[3] J.C. Slater, Adv. Quan. Chem. 1, 35 (1964).

[4] P. Blaha, K. Schwarz, G. Madsen, D. Kvasnicka, J. Luitz, An Augmented Plane Wave Plus Local Orbital Rogram for Calculating the Crystal Properties, 12th Ed., Wien2k, 2012.

[5] J.P. Perdew, K. Burke, M. Ernzerhof, Phys. Rev. Let. 77, 3865 (1996).

[6] H.J. Monkhorst, J.D. Park, Phys. Rev. B 13, 5188 (1976).

[7] A. Elfalaky, S. Soliman, J. Alloys Cmpd. 580, 401 (2013).

[8] I. Ibrahim, I.O. Ali, T.M. Salama, A.A. Bahgat, M.M. Mohamed, Appl. Catal. B 181, 389 (2016). 